\title{
EDITORIAL
}

\section{IAS AND US GAAP - NEW ACTUARIAL CHALLENGES}

A few years ago, if an American actuary, accountant or finance expert crossed the ocean to work for an insurance company on the European continent, this person would likely experience cultural shock. The standards for annual reports and charts of account were worlds apart from the "American Way". The expression "Alpine Accounting" was created to describe what was maybe perceived as hiding treasures away in deep mountain valleys - as it seemed, general practice of companies domiciled close to the Alps. Reserves determined by accountants and underwriters without further actuarial control, fluctuation "reserves", valuation of assets at the lower of purchase and market price, coupled with low official solvency margins and solvency requirements, rudimentary accrual procedures wasn't this just like fishing in troubled waters?

In the meantime, a few years have passed, and a reverse cultural shock is impacting the European side. Managers of financial institutions are faced with an ever increasing pressure for more transparency of their balance sheet. But how can this be achieved if the existing accounting principles do not provide the desired degree of transparency? In more and more cases, it is considered necessary to break cover and adopt yet unknown ways of financial reporting - such as IAS and US GAAP.

US GAAP - short for "United States General Accepted Accounting Principles" - describes a common set of accounting rules applied by US insurance companies - nationwide and independent from particular statutory standards which can vary by state. Other than in Europe, US corporations law normally does not cover financial reporting. As a consequence, the framework for US GAAP was established by the SEC (Securities and Exchange Commission) set up as an independent government agency in 1934. It also satisfies requirements raised by the following additional institutions:

- FASB (Financial Accounting Standards Board)

- EITF (Emerging Issues Task Force)

- AICPA (American Institute of Certified Public Accountants).

As a matter of fact, companies practicing US GAAP accounting are subject to an extensive and strict set of rules, driven by the intention to ensure full and fair disclosure. The resulting system of accounting standards has had a largely evolutionary genesis: Over time, observations of certain practices and transactions triggered new rules designed to mitigate perceived problems and reinstate full transparency of financial statements. 
The foundations of IAS - short for "International Accounting Standards" - go back to 1973. Then, the International Accounting Standards Committee (IASC) was established as an autonomous body to develop and publish binding International Accounting Standards. The aim to grant consistent interpretation in different countries was pursued by the IASC through the creation of broad principles rather than overly detailed rules, dealing only with the substance of transactions. This treatment, together with the fact that the IASC on a stand-alone basis does not have the power to enforce international compliance with IAS, initially led to a heterogeneous and incomprehensive system of rules with definition gaps and different interpretations in different legal environments.

In the beginning of the 90's, the IASC succeeded in eliminating many of the choices of alternative accounting treatments, and the remaining choices were clearly categorized as "benchmark" or "allowed alternatives". Nevertheless, in some areas the rules are still very generic and do not give a clear and detailed answer to some insurance specific questions. So, for the IASC, work is still "in progress".

Under the circumstances, companies applying the new accounting principles in practice need default standards where IAS is silent. Certainly, the creators of IAS did not want to simply imitate US accounting. And indeed, IAS and US GAAP are not completely the same. But although the SEC publicly supports the IASC's project, they applied pressure by stipulating that certain key elements be fulfilled as a prerequisite for their acceptance of the results. The challenge is the production of a core set of comprehensive, generally accepted accounting pronouncements which grant comparability, transparency and full disclosure and are rigorously interpreted and applied. In this situation, many companies adopt the well-defined US GAAP as a default standard. This seems to be the most practical solution.

Now, why would anybody submit voluntarily to procedures such as these, producing additional accounts, parallel to local statutory and tax reporting? Why would a company be willing to add further complexity to the accounting process? What could cause such a change of paradigm, a shift from flexibility and privacy to transparency and publicity?

There is one straightforward reason which holds true for a substantial number of companies: If you want to be listed at the New York Stock Exchange, there is no other way besides producing accounts which follow strictly the SEC requirements. Sure, this is a logical driver of the decision to go to US GAAP accounting. But there are reasons other than listing requirements - more subtle but nevertheless quite powerful.

Analysts and sophisticated investors want to understand what is really going on. They are sick and tired of struggling through the fog of statutory accounts. They are no longer willing to base their recommendations or decisions on guesswork derived from comparing apples and oranges. Ask analysts about their priorities: you will be amazed how often transparency of reports is on top of their wish list! 
Why do companies usually produce management reports on top of their statutory and tax accounting? Apparently because the latter are perceived as an inadequate information base for decisionmaking. Due to lack of transparency, the real issues and opportunities are not always visible. Analysts and investors have the exact same problem.

But what characteristics make a report transparent? The answer according to US GAAP and IAS (despite of all the differences remaining between the two) is a common list of simple and obvious principles:

- Consistent analytic assessment of estimated elements of financial condition and performance

- Going concern (instead of just monitoring the present status)

- Accrual (to reflect economic, contractual, and contingent events instead of just cash flow)

- Fair presentation (e.g. valuation of assets and liabilities)

- Matching (including correct labeling of balance sheet and P\&L items)

- (moderate) conservatism.

Certainly, IAS/US GAAP cannot be considered as the perfect environment for granting ultimate transparency; in particular the strict application of SEC rules is considered quite complicated by many practitioners - too complicated to be transparent. Furthermore, there remain elements of inconsistency or (intentional) conservatism, such as the valuation of real estate versus stocks and bonds or the prohibition of anything resembling discounting of reserves (other than for structured settlements). Nevertheless, the principles promise a high level of realism in the assessment of financial strength and performance, as compared to most statutory accounting rules. If you consider as a yardstick the amount of effort it takes to convert an IAS/US GAAP account into meaningful management information you cannot help discovering that you have got pretty close - at least compared to "Alpine" statutory accounting.

Now, what does all this mean for actuaries and the actuarial role, particularly in Europe? "Job security", I can hear the cynics say, and they are not totally wrong. There is simply no way to apply the new accounting principles properly without the involvement of actuaries. In order to assure that the disclosed information is meaningful, it requires the application of actuarial principles. There is a practical and a formal aspect of actuarial involvement.

First, some of the processes have become too complex to be captured any more by pure means of accounting. Elements which are not exactly known but only estimated play a crucial role in performance and financial conditions. They can only be assessed by actuarial tools and probabilistic techniques. Second, the published figures need to be not only transparent but also credible - which means that there is need for a formal approval process by a skilled individual obliged to act on the basis of clearly defined professional standards: The (appointed) actuary. 
Consequently, we will see more and more companies discovering the need for a corporate actuarial function - even in the continental European non life insurance industry (formerly an "actuary free zone").

So what can be expected from actuaries in the process of IAS/US GAAP reporting? As it can be learned from the US environment, their services are needed particularly in the following areas:

- Premium recognition: There is more to this than just calculating unearned premiums according to some daily pro rata system or monthly method; the task includes estimating ultimate premium, under conditions such as retrospectively rated policies (where the ultimate premium is dependent upon the actual loss experience) or "audit premium" (being adjusted to the size of covered risk).

Calculation of deferred acquisition cost: Costs which are directly related to the acquisition of new and renewal contracts are capitalized and amortized over the term of the policies (for multi-year contracts over the estimated contract duration). This is generally not a very complex task and may greatly resemble the calculation of unearned premium; however, actuaries need to perform profitability tests on the basis of groups of similar insurance contracts to determine a possible premium deficiency. This process can be considered just like a simplified "a posteriori pricing" exercise. Based on such DAC recoverability tests, DAC is immediately expensed when it is not recoverable. Therefore, the actuarial analysis can trigger material accounting decisions.

- Valuation of reserves for losses and loss adjustment expenses: Projecting ultimate claims cost is one of the actuarial core disciplines. It includes trending for effects of inflation and "superimposed inflation" (through social and economic factors), salvage and subrogation, loss adjustment expenses (internal and external), and incurred but not reported (IBNR) claims. The task of the actuary is to produce a "best estimate", a true and fair estimate of the ultimate cost.

This is an important and complex task, and in no case can it be properly treated out of the underwriting and/or accounting area per se. The process includes data selection and grouping, decisions about appropriate methods and a lot of benchmarking and judgement, particularly in the area of reserves for unusual and large claims such as asbestos and pollution related liabilities. The estimate must not include "management reserves", such as reserves for future cat events or margins for conservatism. However, due to the inherent uncertainties in the loss reserving process, there is a range of acceptability around the "best estimate" (usually $\pm 5 \%$ ).

A good reserving actuary needs to develop an understanding of the underlying business and therefore uses information from the underwriting and pricing colleagues. Nevertheless, it is important to keep the reserving function independent; in this respect, it can cause problems if the same actuary who is responsible for reserving is operationally involved in the underwriting process as a pricing actuary. 
- Reinsurance risk analysis: In the IAS/US GAAP environment, outgoing reinsurance is under strict scrutiny. Particularly under US GAAP accounting, each reinsurance contract has to pass the "risk transfer" test to allow for technical accounting as reinsurance. This criterion is crucial particularly when it comes to finite reinsurance agreements or alternative risk solutions. It takes an actuary with both profound skills in risk theory and detailed knowledge and experience in the legal and accounting environment to produce an opinion about the degree of risk involved in a transaction - a crucial decision parameter for the accounting treatment.

So it is clear that the new requirements for actuarial involvement arising from IAS/US GAAP accounting will definitely increase the need for actuaries in the $\mathrm{P} \& \mathrm{C}$ insurance industry. But they also trigger a change in actuarial culture and in the image of the actuarial profession. The institution of a corporate actuary, so far in many countries a requirement only for life business, will become indispensable also for $\mathrm{P} \& \mathrm{C}$ companies - either as a formal requirement ("Appointed Actuary") or just "de facto". It will also become apparent what it takes to turn a mathematician dealing with insurance issues into an actuary: professional conduct and responsibility versus regulatory bodies and the public. In this respect, there is no such thing as "deregulation" - just decentralized regulation with tasks being delegated to the actuaries in the field.

In addition to the formal aspect of professional conduct, there is another challenge on the horizon, based on practical considerations: crossing borders to other disciplines. To play a responsible role in the balance sheet closing process (including sign off), the actuary needs to understand the full picture. As a consequence, financial analysis has conquered its place within the actuarial profession. As previously stated, accounting, risk analysis and design of reinsurance structures must be core competencies. Furthermore, asset/liability management and concepts like Embedded Value, obvious companions for every life actuary, are increasingly familiar to casualty actuaries. Dynamic stress testing has become a regulatory requirement in some countries, particularly in Canada - and finally, Dynamic Financial Analysis (DFA) seems to hold the pole position in actuarial fashion. The actuarial profession has become definitely more challenging - it is fun to be an actuary!

Finally, let me return to a previous analogy: actuaries will help avoid the comparison of apples and oranges. According to Farny, we should not even speak of apples and oranges - it's all apples. The difference is that some put them into a basement corner, while others display them openly in the shop window. And - if I may add - it is the role of the actuaries to put them in the right light, weigh and classify them, and put the price tags on.

BERNHARD ARBOGAST 